\title{
Infografía: etapas históricas y desarrollo de la gráfica informativa
}

\author{
Roberto Gamonal ARroyo \\ Universidad Complutense de Madrid \\ rgamonal@ucm.es
}

\section{Resumen}

Se analizarán distintas representaciones gráficas de información y datos realizando un recorrido histórico de la evolución de la Infografía. Aunque pudiera parecer una disciplina muy moderna, existen numerosos antecedentes que responden a la necesidad humana de comprender la complejidad que nos rodea. Desde antiguos mapas hasta los más actuales gráficos interactivos se puede establecer unas etapas temáticas que nos explican el desarrollo de la visualización de datos y su manera de ordenar, explicar y mostrar una información complicada de la manera más sencilla posible.

Palabras clave: Infografía, visualización de datos, gráficos informativos, representaciones gráficas.

\section{Infographic: historical and developmental stages of the graphical information}

\begin{abstract}
We will analyze different graphical representations of information and data by performing a historical overview of the evolution of Infographics. Although it might seem like a very modern discipline, there are numerous precedents that respond to human need to understand the complexity that around us. From old maps to the most current interactive graphics can establish thematic stages we explain the development of data visualization and how to order, explain and show the complicated information as easily as possible.
\end{abstract}

Keywords: Infographics, data visualization, information graphics, graphic representation

\section{Referencia normalizada:}

Gamonal Arroyo, R. (2013) Infografía: etapas históricas y desarrollo de la gráfica informativa. Historia y Comunicación Social. Vol. 18. № Especial Diciembre. Págs. 335-347.

Sumario: 1. Introducción. 2. Metodología. 3. La imagen del mundo. 4. Comunicación del conocimiento. 5. La simplificación de la representación de los datos. 6. El control de la abundancia y la complejidad de la información. 7. Conclusión.

\section{Introducción}

La Infografía va más allá de la mera creación de gráficos. Su principal objetivo es convertir lo complejo en sencillo y explicar lo difícil de la forma más clara posible utilizando el lenguaje gráfico. Su materia prima es la información y los datos son sintetizados y transformados a códigos visuales para que de un solo vistazo se pueda comprender la realidad que se muestra. 
Ante la enorme avalancha de información y de datos a las que estamos sometidos se hace necesario ordenar y estructurar para convertirlos en fuente de conocimiento útil, inteligible y transferible. El trabajo con los datos de manera estadística y rigurosa acerca la labor del periodista a la del científico. En ambas profesiones se busca explicar lo que se investiga a través de la demostración y de la búsqueda de una correlación o conexión entre variables que proporcionen un resultado.

Las representaciones gráficas son también importantes porque nos ayudan a comunicar conceptos abstractos como el tiempo, el espacio, las categorías y la jerarquía. También nos permiten comprender la evolución diacrónica, la situación, la relación entre elementos y su importancia por comparación.

Esto no es nada nuevo. El ser humano siempre ha sentido la necesidad de comunicarse de forma gráfica o visual para explicar cosas que les resulta complicado hacerlo solamente con palabras. De hecho, la expresión "ser gráfico" significa ser claro. Estos recursos han sido aprovechados para representar aquello que nos rodea y poder entenderlo mejor.

\section{Metodología}

En este artículo se verá cómo la forma de mostrar los datos o la información mediante el lenguaje gráfico no sólo responde a la evolución tecnológica de los medios de reproducción, sino también a un modelo de pensamiento imperante en función de la época histórica. Se mostrarán algunos ejemplos y se harán análisis de casos que han sido hitos para el desarrollo de la Infografía como disciplina.

El recorrido histórico estará dividido en épocas en las que se muestra un cambio en las formas de pensar y, por lo tanto, también un cambio en las formas de representación que va desde lo figurativo y realista con todo lujo de detalles a la simplificación y abstracción de la información.

\section{La imagen del mundo}

La visión que el ser humano tiene de aquello que le rodea ha ido cambiando a lo largo de los tiempos. Según Grombrich (1990: 22), las representaciones prehistóricas de escenas de cazas respondían a una finalidad de aprehensión de la realidad. Tenían un carácter mágico ya que se dibujaban los animales que iban a cazar con la esperanza de que así podrían atraparlos. Los griegos y los romanos basaban sus representaciones en el concepto aristotélico de mímesis. La imitación de la realidad era idealizada mediante el uso de los cánones que buscaban la perfección y la belleza divinas.

Se puede apreciar en estas primeras épocas una visión teocentrista en la que no se produce una diferencia entre el mundo artificial creado por el ser humano y el mundo 
natural creado por una divinidad. Esto se puede ver claramente en los primeros mapas en los que se utiliza imágenes de representaciones religiosas. Un ejemplo es el mapa de Ptolomeo (siglo II) en el que la tierra está rodeada de ángeles que están soplando y que representan metafóricamente a los vientos.

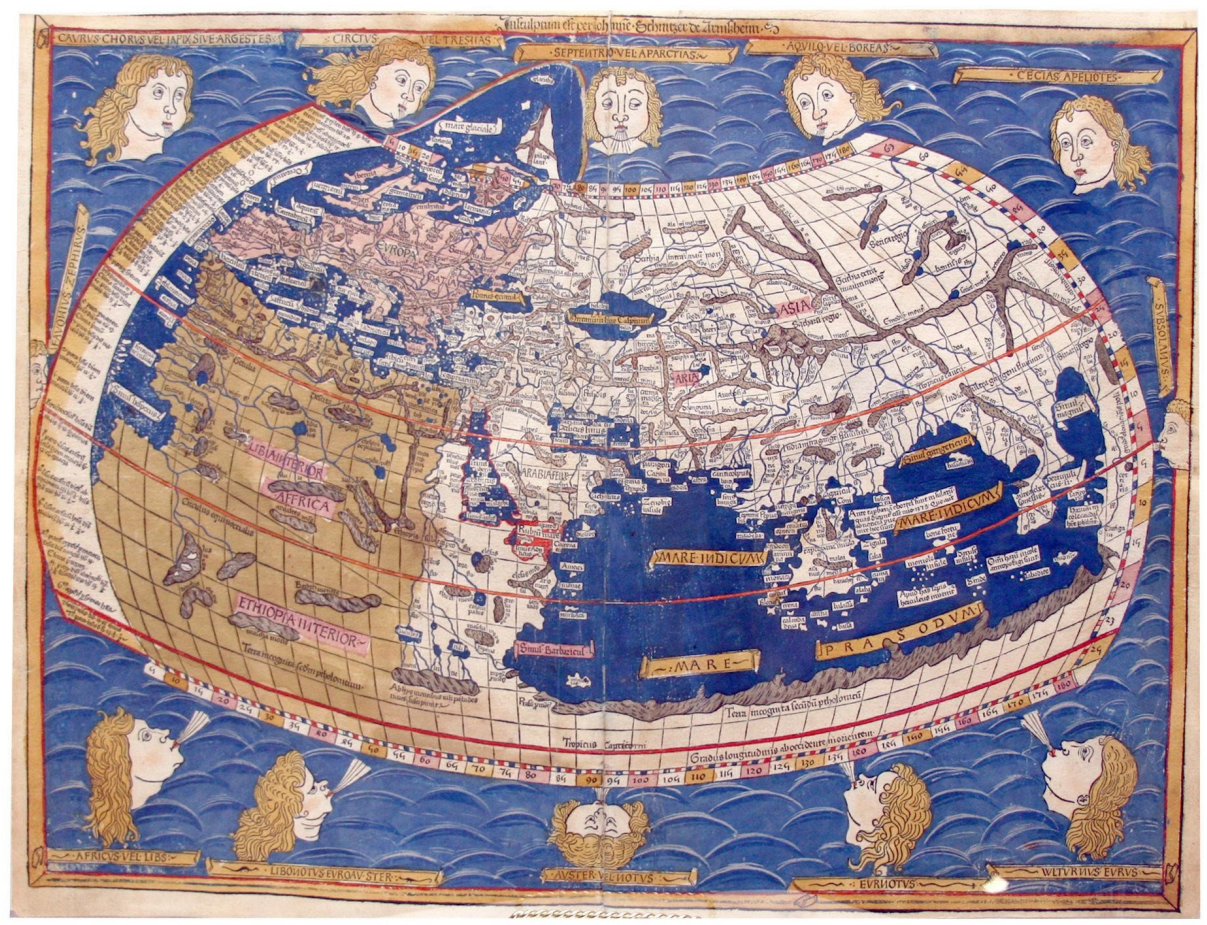

Figura 1. Reproducción del mapa de Claudio Ptolomeo, geógrafo y astrónomo del siglo II.

La Edad Media tuvo también una fuerte influencia religiosa y no había distinción entre lo divino y lo humano. Lo segundo responde a lo primero. Tanto es así que, más que crear, lo que se hacía era recrear el mundo natural que se ajustaba a la perfección divina. Como explica Martín Serrano (2008: 33), se usaban técnicas para reproducir la naturaleza a escala humana, nunca para suplantarla por un medio artificial creado por las personas. Las creaciones naturales y humanas eran ambas expresiones de la grandeza de un dios. El ser humano es simplemente el ejecutor de los designios divinos. Del mismo modo que la creatividad se consideraba una cualidad propia de un dios, el progreso era considerado como un pecado de soberbia.

La construcción de un mundo artificial era entrar en oposición al mundo natural, la gran obra divina. Según esta visión, lo natural es todo aquello que se puede captar mediante los sentidos y lo que no se puede ver es considerado fruto de la magia. Así es cómo se percibían los procesos químicos que denominaban alquimia: como si fuera brujería. 
La única tecnología para el registro, conservación y difusión del conocimiento era la escritura manual, por lo que había muy poca distribución de la información. Los escasos libros que existían eran manuscritos y, por lo tanto, piezas únicas, ya que su reproducción era muy limitada. Los escasos ejemplares eran realizados por monjes escribanos que tardaban meses o incluso en años en copiar los textos sagrados. Los iluminadores se encargaban de realizar las ilustraciones necesarias o espectaculares capitulares con las que se iniciaban los textos.

Era, pues, un proceso laborioso y lento a cuyo resultado sólo podían tener acceso unos pocos, generalmente la nobleza y el clero. Unos porque tenían el dinero suficiente como para encargar un ejemplar y otros porque su misión era hacer estos libros y custodiarlos. Los contenidos eran única y exclusivamente de carácter religioso, lo que hacía que el libro medieval fuera considerado sagrado. La transmisión del conocimiento no era fomentada y la Iglesia era la encargada de proteger la cultura enclaustrándola dentro de los monasterios. La única manera de difusión era la oral y eso suponía un registro deficiente y una conservación de la información que era cambiante y dada a las tergiversaciones.

Ante una mayoría de población que no sabía leer, la lectura sólo era posible de forma pública y en común generalmente realizada en actos religiosos escuchando lo que el sacerdote leía en los textos sagrados y que posteriormente interpretaba sin dar lugar a ninguna opinión o posibilidad de discusión.

\section{Comunicación Del Conocimiento}

En el Renacimiento se produce un cambio en la manera de pensar y de entender el mundo propiciado por los avances científicos y tecnológicos que se producen en esta época. El Humanismo pone su foco de atención en el ser humano y en lo que es capaz de lograr a través de descubrimientos que le acercan más a la comprensión del mundo en el que vive. Se pasa del teocentrismo al antropocentrismo.

Lo que antes parecía producto de la magia encuentra en esta época explicación. Se empiezan a entender fenómenos naturales que no son perceptibles a la vista humana a través de principios universales que son formulados de manera abstracta mediante un predominio de la razón frente a los sentidos.

Las Matemáticas y la Geometría son disciplinas con un enorme desarrollo en esta época con dos elementos clave que ayudan a entender el mundo: el eje cartesiano y la perspectiva. En ambos casos se sigue el principio básico de que para resolver un problema complejo, lo mejor es dividirlo en partes más pequeñas. El ser humano encuentra en la Naturaleza formas y proporciones geométricas que imita y pone a su servicio para crear cosas nuevas. Se fija en cómo vuelan los pájaros, cómo crecen los pétalos de las flores, cómo es la forma de la concha de un caracol, etc... 
Con la imprenta se amplía la difusión del saber. Algo que en principio chocaba con los intereses de la Iglesia que deja de detentar el monopolio de la cultura para pasar a las universidades. Los libros llegan a un poco más de gente y se abren a otros conocimientos y saberes de la época renacentista para dejarse de ser monotemáticos en torno a lo religioso.

La expansión de la imprenta por el continente europeo tiene diversas consecuencias. Una de ellas es la Reforma Protestante que promueve la lectura individual de la Biblia y, por tanto, también la interpretación individual y no impuesta por la Iglesia como ocurrían en la Edad Media. Ante el conflicto político y religioso que causó el pensamiento de Lutero, los poderes ejecutivos quisieron controlar la imprenta a través de leyes en las que se concedían licencias a quienes los monarcas consideraban oportuno y se comenzó también a ejercer la censura.

Con el aumento de la reproducción mediante la impresión se multiplica exponencialmente el conocimiento y permite el progreso científico en disciplinas que explican la vida y la Naturaleza desde la perspectiva del ser humano y no desde el origen divino. Proliferan los tratados relacionados con las Ciencias Naturales como Medicina, Biología, Zoología y Botánica que ahora contienen numerosas ilustraciones realizadas por grabadores para apoyar los textos. Destaca especialmente en esta tarea Alberto Durero, que realizó numerosos grabados que estudiaban la anatomía humana y distintas especies de la flora y la fauna.

La imagen en grabado se convierte ahora en un elemento que se puede reproducir tantas veces como se quiera al igual que el texto con la tipografía. Su capacidad pedagógica y de difusión de la cultura tampoco pasó desapercibida para la Iglesia que aprovechó el poder icónico para evangelizar a un pueblo que seguía siendo la mayoría analfabeto. Según José Luis Valero (2001: 34-44), el mejor ejemplo son los frescos de la Capilla Sixtina pintados por Miguel Ángel y encargados por el papa Julio II, cuyo objetivo era crear una "explicación visual" de la creación y del juicio final para un público iletrado.

Con todos estos avances en el conocimiento y en la ciencia también se busca la aplicación práctica para la creación de utensilios y herramientas que faciliten un poco más la vida del ser humano. Quizá el paradigma de esta visión sea Leonardo de Vinci, que supo poner en común los conocimientos científicos con la representación gráfica y artística para explicar y hacer comprensibles ideas y montajes complejos. 


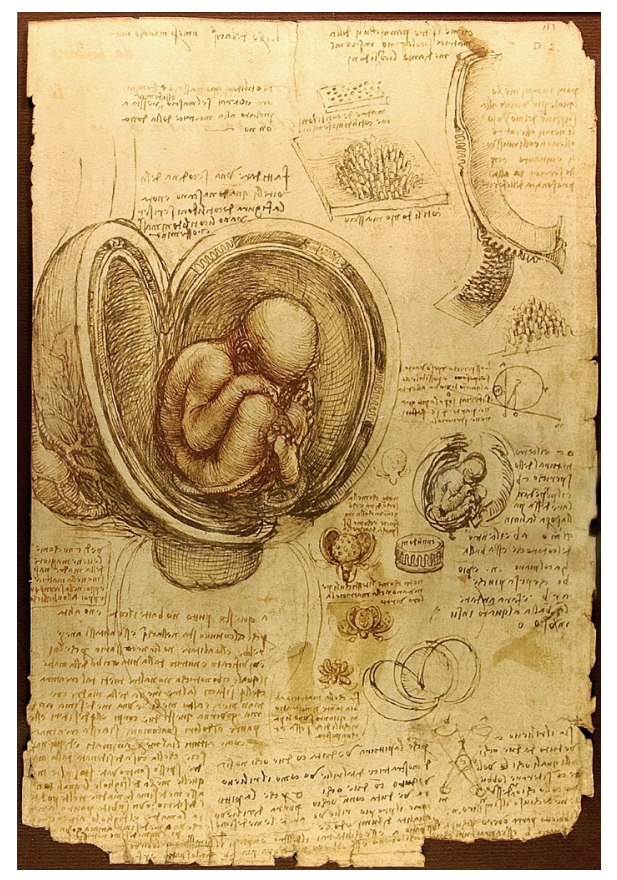

Figura 2. Estudio del embrión realizado por Leonardo da Vinci.

\section{La simplificación de la representación de los datos}

Sheila Pontis (2007) afirma que en los siglos XVI y XVII se estudiaron las mediciones físicas de tiempo, distancia y espacio. Estos avances vienen dados porque las disciplinas científicas tienen la necesidad de conseguir datos e información de una manera más exacta y se crean nuevas técnicas e instrumentos para la medición y la observación.

Estos progresos se recogen en las enciclopedias y diccionarios que aglutinan todos los conocimientos en todas las áreas del saber que son profusamente ilustrados con virtuosos grabados. Una de estas obras gigantescas es L'Encyclopédie, ou Dictionnarie Raisonné des Sciences, des Arts et des Métiers, editada por Diderot y D'alambert entre 1751 y 1772 . Veintiún años para realizar 33 volúmenes con 2.900 ilustraciones sobre el comercio, la industria y los oficios.

Surgen también en esta época los primeros periódicos que también utilizaban los grabados para ilustrar sus noticias. Según Valero (2012: 33), la primera imagen publicada en prensa salió en The Daily Courant en 1702 y se trataba de un mapa de la bahía de Cádiz en el que se contaba el conflicto con los británicos durante el reinado de Felipe V. Otro ejemplo es el publicado en 1740 por el Daily Post en el que mediante un mapa se describe el ataque del almirante inglés Vernon a la ciudad de Portobello en una intervención militar contra el tráfico de oro español. 
Peltzer (2001: 110) considera que la primera infografía periodística fue publicada en 1806 por The Times. En ella se explicaba con claridad el asesinato cometido en una mansión cercana al río Támesis. La infografía constaba de dos imágenes: una vista frontal de la casa y un plano con las diferentes estancias. Acompañando a las imágenes, sendos titulares y una leyenda que explica cada una de las habitaciones. En el plano de la casa se dibuja la ruta que siguió el asesino hasta llegar a la biblioteca e incluye un dibujo lineal de la trayectoria de la bala.

También de este periódico londinense data el primer mapa meteorológico en 1875. Un dibujo de línea de las islas británicas y parte de Europa en el que se dibujan las isobaras en línea discontinua, las flechas indicando la dirección del viento, datos numéricos de temperatura y descripción textual del estado de la mar.

Además de las representaciones gráficas de información y datos en las publicaciones periódicas durante el siglo XVIII se va desarrollando como disciplina científica la Estadística y otras disciplinas sociales como la Demografía. Con el nacimiento de la Geometría Descriptiva y el sistema Monge (también llamado sistema diédrico), se puede representar la realidad en tres dimensiones sobre un plano a través de la planta, el alzado y perfil.

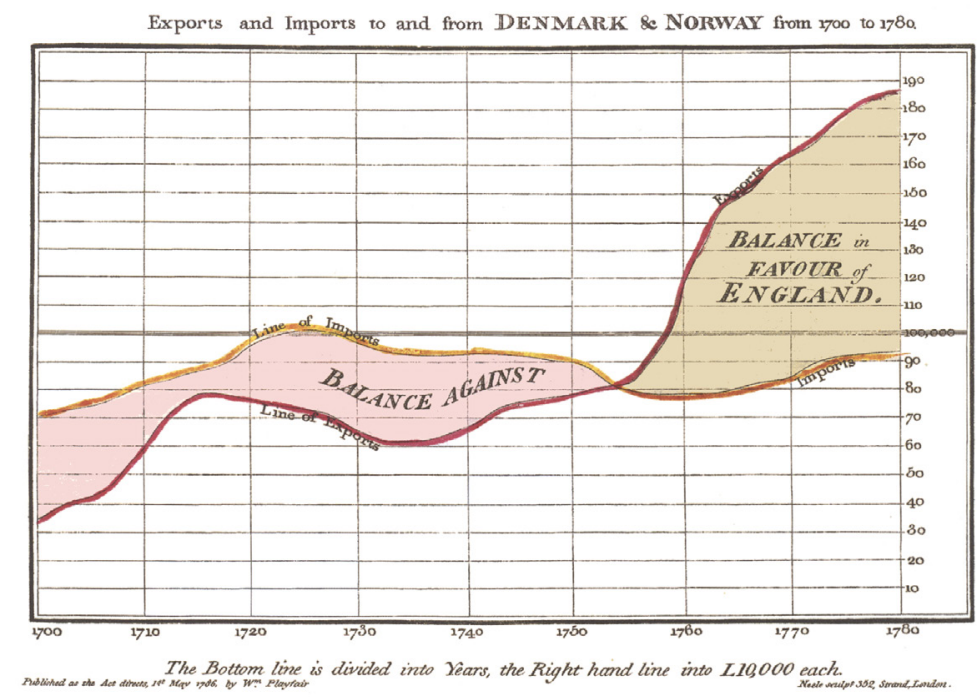

Figura 3. Gráfico de línea que muestra comparativamente datos del comercio exterior de Inglaterra. Realizado por William Playfair en 1786.

La evolución del estado moderno hace que se incrementen las necesidades de tomar decisiones en base a datos demográficos y económicos. Hasta entonces, la manera más sencilla para mostrar los datos eran las tablas, pero en 1786 el ingeniero y economista escocés William Playfair, considerado el padre de la Estadística Gráfica, comenzó a utilizar gráficos y diagramas de línea, barra y tartas para representar cifras 
económicas (Rendgen, 2012: 11). En uno de sus gráficos más conocidos consigue mostrar de forma clara a través de un diagrama de líneas cómo ha evolucionado positivamente el balance del comercio exterior inglés comparando las importaciones y exportaciones a Dinamarca y Noruega.

El siglo XIX supone un crecimiento exponencial en la información gráfica y también se propicia una importante renovación en las formas visuales de representación de los datos. La información pasa de mostrarse de forma figurativa o realista a la abstracción. Esto enriquece enormemente las posibilidades comunicativas. Además, los datos ya no son solamente números y los gráficos pasan a recoger información de diferentes tipologías compuestas de texto, imagen y formas geométricas. Ya no sólo se pueden ver las cantidades, sino que también se establecen relaciones cualitativas entre las distintas variables.

Un ejemplo de esta renovación en la manera de contar las cosas visualmente es la infografía realizada en 1869 por el ingeniero francés Charles Joseph Mainard (Rendgen, 2012: 11). Mediante una nueva forma gráfica, el mapa de flujo, que le permite establecer relaciones de movimiento y evolución, explica de forma muy didáctica el fracaso de la campaña militar de Napoleón Bonaparte durante la invasión de Rusia en 1812. En este gráfico se combina ingeniosamente un mapa que detalla el avance de las tropas hacia Moscú con una línea marrón que va disminuyendo progresivamente según se van acercando a la capital rusa y una línea negra que simboliza la retirada. El resultado es que Bonaparte comienza su acción militar con 422.000 soldados y regresa con sólo 10.000. La infografía incluye además un segundo gráfico que muestra las gélidas temperaturas sufridas durante la campaña estableciendo una clara correlación con la drástica disminución de los soldados. Aunque contiene un breve texto explicativo, no es necesario ya que se trata de una excelente representación visual y un magistral ejercicio de síntesis una gran cantidad de información y datos que quedan muy bien resumidos y contados de forma gráfica.

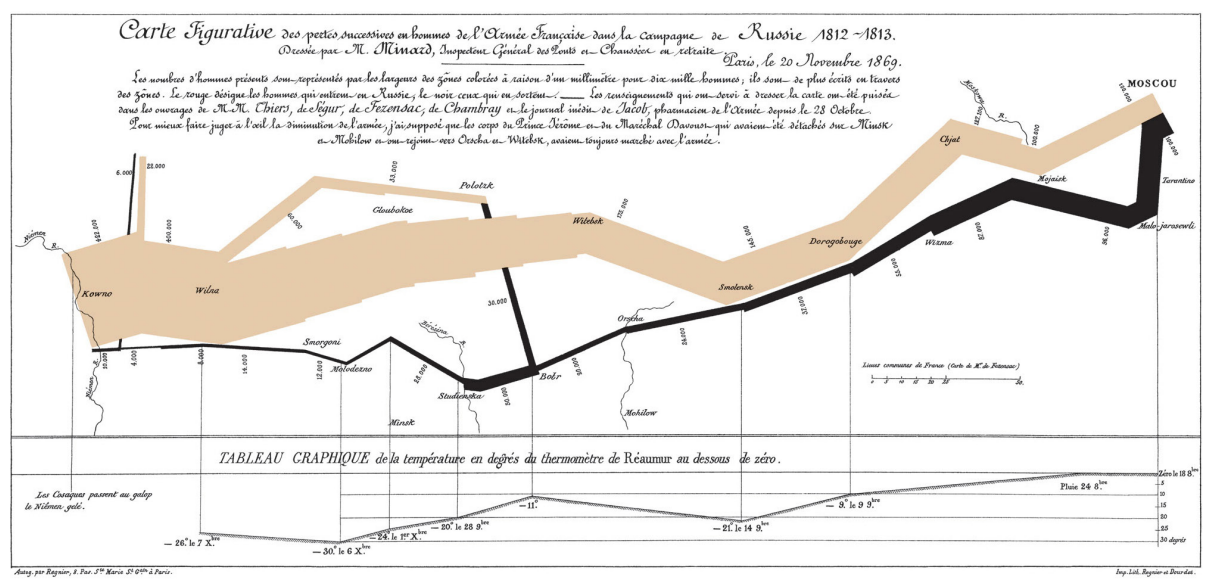

Figura 4. Infografía de Mainard de 1869 sobre la invasión de Rusia de las tropas napoleónicas. 
En el siglo XX las esquematizaciones van mejorando su aspecto visual a través de la ayuda de profesionales expertos en el terreno del Diseño Gráfico. Este es el caso de Otto Neurath, sociólogo y filósofo austriaco, que con la ayuda del ilustrador y diseñador alemán Gerd Arntz, creó ISOTYPE (International System of Typographic Picture Education). Consciente del poder de la imagen como lenguaje universal, Neurath idea un sistema estandarizado de representación basado en pictogramas o iconos que no requerían de ningún texto para ser comprendidos (Vossoughian, 2008: 91). Gracias a un diseño simplificado se reduce al máximo la expresión y se obvian detalles. Estos pictogramas podían combinarse y agruparse, por ejemplo, formando filas para indicar la cantidad exacta en vez de hacerlo con un gráfico de barras. Los iconos también podían ser reutilizados para crear nuevos conceptos que se sumaban a una colección de más de 4.000 pictogramas.

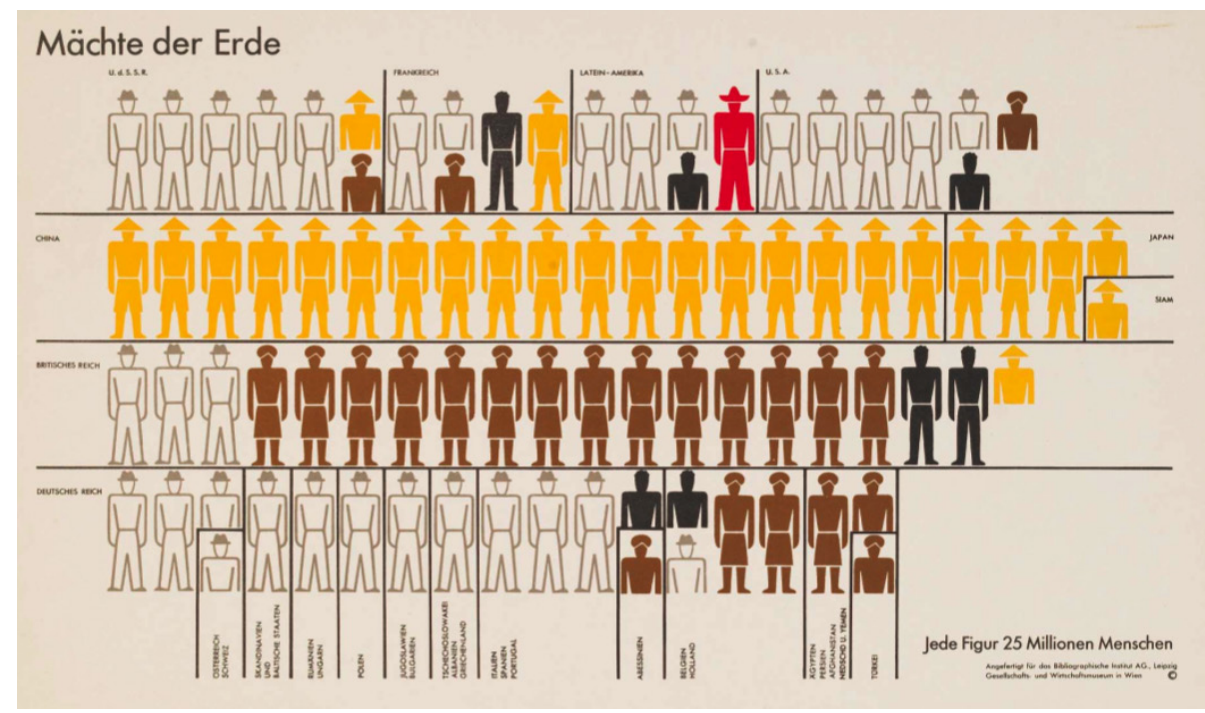

Figura 5. Gráfico de ISOTYPE que representa las razas humanas que viven en diferentes países.

El progreso del siglo XX se nota especialmente en la mejora de las comunicaciones y los transportes. Las infraestructuras aumentan y los viajeros necesitan información clara y concisa para saber dónde se encuentran y cómo llegar a su lugar de destino. Nacen así los primeros mapas esquemáticos de las redes de transporte que no se basaban en criterios cartográficos y geográficos.

En 1933 un ingeniero electrónico llamado Henry Beck crea un mapa del metro de Londres sin tener en cuenta ninguna norma cartográfica. Dibujó el mapa como si fuera un circuito eléctrico usando líneas identificadas cromáticamente y con formas ortogonales (verticales, horizontales y oblicuas en ángulo de 45 grados). Posicionó las estaciones teniendo en cuenta el espacio disponible en su mapa y no la distancia real que había entre ellas. 
Beck pensó en cómo el usuario del metro se enfrentaba a una red muy compleja y diseñó un mapa sencillo que proporcionaba de forma clara información de cómo llegar de un sitio a otro, qué línea tomar y por cuáles estaciones pasar.

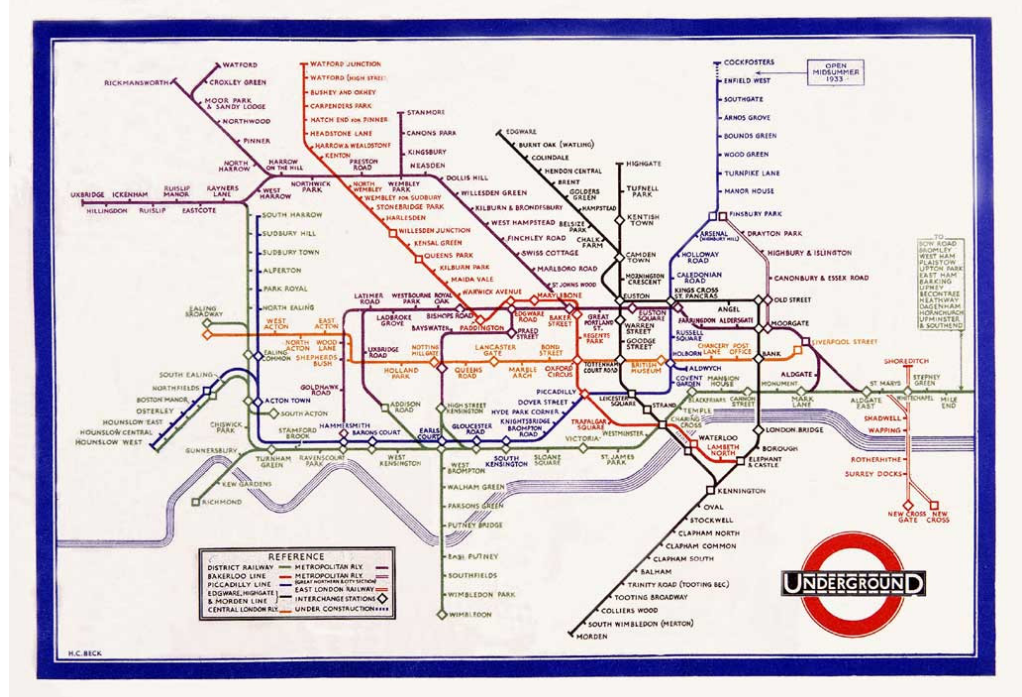

Figura 6. Plano del metro de Londres realizado por Henry Beck en 1933.

\section{El control de la abundancia y la complejidad de la información}

Abraham Moles (1989: 119-129) considera que, ante la enorme complejidad existente en el mundo artificial creado por el ser humano, el objetivo principal es hacer legible y comprensible todo aquello que nos rodea.

Antes de la llegada de Internet a nuestras vidas, Richard Saul Wurman nos hablaba de "arquitectura de la información" y advertía de un crecimiento exponencial de la cantidad de información disponible y planteaba la necesidad de profesionales cuyo objetivo fuera organizarla, darle sentido y presentarla de forma coherente, sistemática y comprensible (Cairo, 2011: 30). Para Wurman, los arquitectos de la información combaten la ansiedad que puede producir el hecho de que tengamos tanta cantidad de datos e información útiles e interesantes al alcance de la mano, pero que no damos abasto para asimilarla.

La irrupción de la Informática para la gestión de los datos estadísticos y también para su representación gráfica revoluciona y multiplica las posibilidades. Aunque en muchos casos, como denuncia Tufte y otros autores, son gráficos muy bonitos, pero poco rigurosos (Rendgen, 2012: 9). El ordenador, el software informático, la programación y la animación permiten crear visualizaciones de datos de manera más fácil, 
pero en ocasiones, se obvia que el objetivo es transmitir una información de forma simple y no llamar la atención.

En contrapartida a un uso efectista de la tecnología, ésta posibilita nuevas fórmulas narrativas para contar de formas diferentes unos datos. Las infografías ya dejan de ser casi exclusivas de la prensa escrita y pasa también a las pantallas, adoptando el lenguaje audiovisual y otras sustancias expresivas más allá de la imagen fija como el movimiento y el sonido.

Los recursos que proporciona la interactividad han propiciado la aparición de infografías digitales y multimedia que han supuesto nuevas representaciones gráficas que dan la posibilidad a los usuarios de crear su propia experiencia de lectura y de ampliación de consulta de fuentes externas. En las actuales infografías digitales convergen todo tipo de lenguajes como el cómic, la música y el cine para potenciar la expresividad de la información. Los lenguajes de programación además aumentan las oportunidades de interacción dando el poder al propio lector para elegir su manera de leer, descubrir y explorar la información.

Un ejemplo es el gráfico interactivo de abril de 2013 que explica el atentado producido en la maratón de Boston sobre la aplicación de Google Maps que muestra la persecución policial para coger a los responsables. El usuario puede acercar más su punto de vista e incluso ver las calles como si estuviera allí mismo.

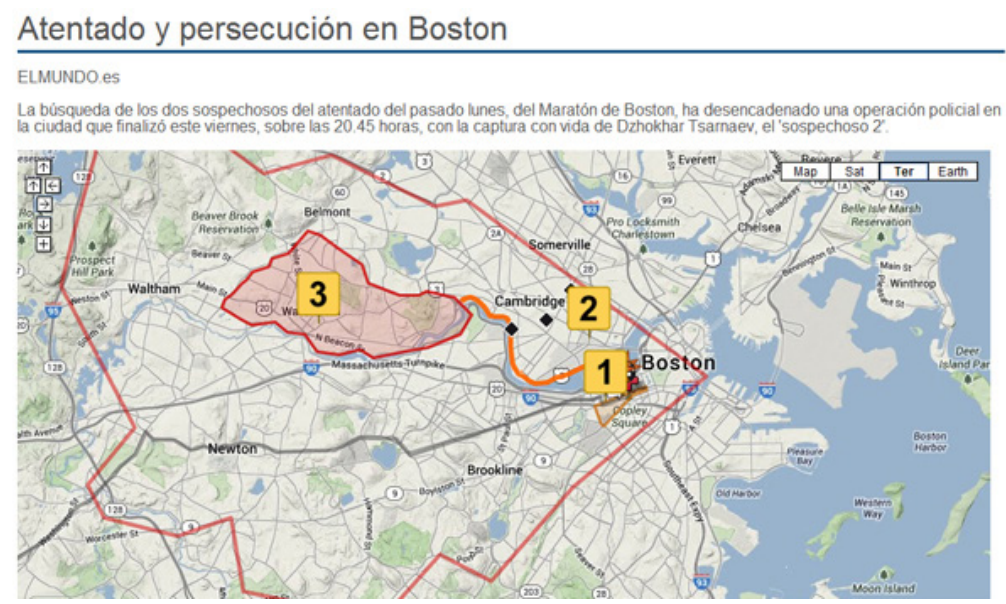

Figura 7. Gráfico interactivo sobre el atentado de Boston publicado por El Mundo.es

Pero el cambio más profundo que estamos viviendo en estos momentos es que los datos también se han convertido en interactivos, es decir, en una materia prima de información que es accesible, que se puede comparar, interpretar y comentar. Ahora la representación gráfica de los datos y la visualización de la información han dejado de ser territorio exclusivo del periodista o el científico y está abierto a cualquier ciudadano. La conciencia y exigencia del acceso libre a los datos de las instituciones públicas ha derivado en un movimiento civil de empoderamiento del ciudadano que 
cada día está más informado y capacitado para reivindicar el cumplimiento de los derechos y deberes.

Esto también ha obligado a replantearse el papel del periodista como profesional de la información que busca la noticia. El llamado "Periodismo de Datos" viene a poner énfasis en la objetividad de éstos y en el cruce y conexión para buscar posibles relaciones que pueden explicar los hechos. Y en este nuevo periodismo la visualización tiene una enorme importancia.

Un ejemplo de este nuevo enfoque es el proyecto "España en llamas" llevado a cabo por Juan Elosua que parte de bases de datos nacionales sobre incendios forestales producidos entre los años 2001 y 2011. Nos muestra sobre el mapa de España los incendios que se han producido en este periodo de tiempo y la cantidad de hectáreas que se han perdido. Un total de 1.679 incendios, de los cuales la mayoría eran intencionados, más de 750.000 hectáreas calcinadas que suponen unas pérdidas económicas de casi 650 millones de euros.

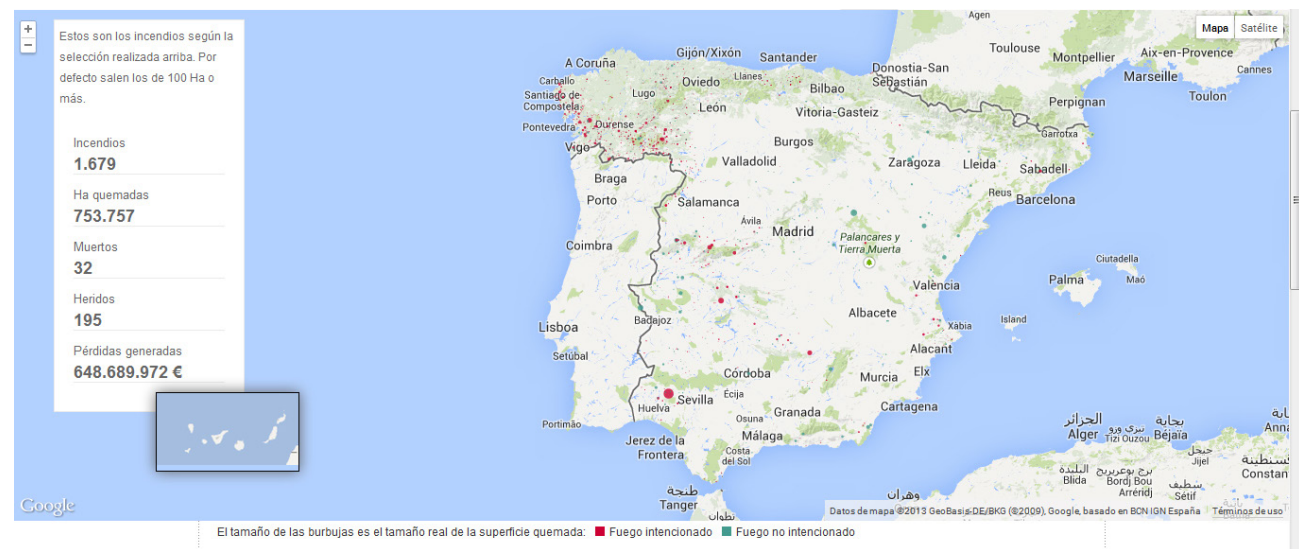

Figura 7. "Proyecto España en llamas", visualización de los incendios forestales desde el 2001 al 2011.

\section{Conclusión}

A lo largo de este recorrido histórico hemos podido comprobar cómo la manera de representar gráficamente la información está fuertemente influenciada por los modelos de pensamiento imperantes y los avances tecnológicos de una época. La infografía tiene como funciones representar el mundo que nos rodea, transmitir el conocimiento, sintetizar la información y dominar la complejidad. Y todo ello responde a la necesidad innata en el ser humano de hacer inteligible todo aquello que le rodea para poder aprehenderlo. Porque la comprensión precede a la acción. 
En una época en la que vivimos una auténtica avalancha de datos que nos llegan de forma incoherente, desorganizada e incontrolada, saber filtrarlos y darles una estructura lógica nos ayuda a tomar decisiones de una manera óptima.

Si somos capaces de verlo, somos capaces de entenderlo. O como decía Albert Einstein: "Si no puedes explicarlo de manera sencilla es que no lo has entendido lo suficientemente bien". Este es el objetivo principal de la infografía y de las visualizaciones de datos: sintetizar una gran cantidad de información y que esta se pueda comprender claramente con un solo vistazo.

\section{Referencias bibliográficas}

CAIRO, A. (2011). El arte funcional. Infografía y visualización de información. Madrid: Alamut.

DONDIS, D. A. (2004): La sintaxis de la imagen. Introducción al alfabeto visual. Barcelona: Gustavo Gili.

GOMBRICH, E. (1990): Historia del arte. Madrid:Alianza.

MARTÍN SERRANO, M. (2008): La mediación social. Madrid: Akal.

MOLES, A. (1989): "The legibility of the World: a project of Graphic Design". En MARGOLIN, V. (ed): Design Discourse. History, Theory, Criticism. Chicago:University of Chicago Press. p. 119-129.

PELTZER, G. (2001): Periodismo iconográfico. Madrid: Ediciones Rialp.

PONTIS, S. (2007): "La historia de la esquemática en la visualización de datos". En Visualizar 07. Disponible en: http://medialab-prado.es/article/la_historia_de_la esquematica_en_la_visualizacion_de_datos_por_sheila_pontis_. [10-08-2013]. RENDGEN, S. $\overline{(2012)}$ : Information Graphics. Colonia: Taschen.

VALERO SANCHO, J. L. (2001): La infografía. Técnicas, análisis y usos periodísticos. Barcelona: Universidad Autónoma de Barcelona.

(2012): Infografia digital. La visualización sintética. Barcelona: Editorial Bosch. VOSSOUGHIAN, N. (2008): Otto Neurath. The language of the Global Polis. Rotterdam: NAi Publishers.

\section{El autor}

Roberto Gamonal Arroyo. Diseñador y profesor e investigador universitario. Es doctor en Creatividad Aplicada y máster en Diseño por la facultad de Bellas Artes de la UCM. Licenciado en Ciencias de la Información de la UCM donde es actualmente profesor asociado en el departamento de Periodismo II impartiendo asignaturas relacionadas con el diseño en la comunicación periodística. Pertenece a los grupos de investigación SOCMEDIA y Ciberimaginario donde aporta su visión como experto en diseño en diferentes proyectos de investigación y desarrollo. 